\title{
SANTUARIOS MARIANOS EN VALLE Y EN BELÉN. CATAMARCA, 1640-1700*
}

\author{
MARIAN SANCTUARIES IN VALLE AND BELÉN. CATAMARCA, 1640-1700
}

\author{
Telma Chaile**
}

\begin{abstract}
Nos proponemos abordar, de manera comparativa, los procesos de conformación de los santuarios marianos de la Concepción/del Valle en el centro-oeste catamarqueño y de Belén en el oeste, desde las dos últimas décadas de la primera mitad del siglo XVII hasta la culminación de la centuria. Ambos santuarios aparecen vinculadas al proceso de colonización española al dar cuenta de formas de configuración en donde la ocupación estuvo ligada al desarrollo de espacios religiosos, cuyas advocaciones titulares coincidieron con los topónimos.
\end{abstract}

Palabras claves: Catamarca, santuarios marianos, Valle, Belén, siglo XVII.

We propose to approach, in a comparative way, the processes of conformation of the Marian sanctuaries of the Conception/ of the Valley in the center-west catamarqueño and of Bethlehem in the west, from the last two decades of the first half of the 17th century to the culmination of the century.Both sanctuaries appear linked to the Spanish colonization process by giving an account of configuration forms in which the occupation was linked to the development of religious spaces, whose titular advocations coincided with the toponyms.

Key words: Catamarca, Marian sanctuaries, Valle, Belén, 17th century.

La conformación territorial de Catamarca como un espacio en proceso de colonización durante el siglo XVII comprendió núcleos de asentamiento en las localidades de Valle y Belén en cuyo afianzamiento confluyeron varios factores (Guzmán 2016:27-51), entre estos se encuentran los religiosos para los que es importante considerar el influjo de los santuarios ${ }^{1}$ marianos. El Tucumán fue ocupado de manera disímil hasta mediados del siglo XVII debido a la resistencia indígena Calchaquí, la que dificultó el control del oeste de la gobernación y determinó la conformación de fronteras en los espacios que dependían de las jurisdicciones de las ciudades fundadas. El sector comprendido al oeste de las ciudades de San Miguel de Tucumán y de Santiago del Estero y al norte de la ciudad de Todos los Santos de La Nueva Rioja tenía esa condición de frontera. En ese espacio ejercieron jurisdicción autoridades de estas ciudades y de Londres, núcleo situado en el interior del mismo, situación que se mantuvo hasta la fundación de la ciudad de San Fernando del Valle de Catamarca a fines del siglo XVII (Lorandi y Schaposchnik 1990:180; Vázquez 2009:19-21).

La relación entre el culto a la Virgen del Valle y el poblamiento del sector centro-oeste del Valle de
Catamarca fue un tópico planteado desde fines de la centuria del siglo XIX (Soprano, 1889; Larrouy 1916) y retomado por investigaciones posteriores (Lorandi y Schaposchnik 1990; Capurro 2017). Estos trabajos indagaron respecto del culto a partir de la guerra Calchaquí, la incorporación de indígenas a la sociedad colonial, la importancia de los milagros de la Virgen y el proceso de apropiación hispanocriolla. Aquí nos interesa abordar, de manera comparativa, los procesos de conformación de los santuarios de la Concepción/del Valle en el centro-oeste catamarqueño y de Belén en el oeste, desde las dos últimas décadas de la primera mitad del siglo XVII hasta la culminación de la centuria. Ambos santuarios aparecen vinculadas al proceso de colonización española al dar cuenta de formas de configuración en donde la ocupación estuvo ligada al desarrollo de espacios religiosos, cuyas advocaciones titulares coincidieron con los topónimos. La vinculación entre congregación de pobladores y lugares de culto, junto con el acrecentamiento del prestigio de las imágenes que albergaban, fue una constante en Europa y en América (Christian 1991; Gutiérrez-Cortines Corral y Griñán Montealegre, 1996; Feedberg 2009, Fogelman 2002; Chaile 2011; Capurro 2017).

\footnotetext{
* Forma parte del proyecto CIUNSA 2476 y Proyecto IDEA 056CO de la UE ICSOH-CONICET-UNSa.

** ICSOH-CONICET, UNSa, Argentina. Correo electrónico: telmachaile@gmail.com
} 
Los agentes coloniales promovieron el culto a santos y a la Virgen María también en espacios de frontera donde el asentamiento español tuvo una dinámica con oscilaciones (Lorandi y Schaposchnik 1990; Fogelman 2002; Chaile 2011). Aun cuando la mayoría de las ciudades fundadas en el Tucumán se nominaron con nombres de advocaciones de santos, los santuarios que se conformaron fueron aquellos con títulos que honraban a la Virgen María. Para Salta, otro espacio del Tucumán, se planteó que el culto a la figura de santos, relacionada a patronatos de ciudades y localidades ${ }^{2}$, no se configuró con connotaciones consideradas prodigiosas. Las referencias de este tipo aparecieron ante situaciones de crisis que hicieron peligrar el sostenimiento de los poblados, entre estas, las de carácter bélico evidenciaron importancia creciente. Determinadas advocaciones marianas permitieron a pobladores garantizar la resolución de dificultades en varias jurisdicciones del Tucumán, consagradas en acciones de protección y ayuda diversa (accidentes, desastres naturales, enfermedades) y la participación en enfrentamientos con indígenas que resistían la conquista en los siglos XVII y XVIII (Chaile 2011:35-45).

En el espacio catamarqueño, los títulos de los dos santuarios remiten a advocaciones diferentes. En el caso del Valle se trata de Nuestra Señora de la Purísima Concepción, una de las advocaciones más promocionadas por la monarquía española y algunas órdenes religiosas (Anrup 1998) ${ }^{3}$. Representa a la Virgen en el misterio de Concepción Inmaculada, es decir, concebida sin pecado original ${ }^{4}$. La imagen es una escultura que se encuentra "de pie, la media luna bajo sus plantas, las manos juntas ante el pecho, mirando al cielo, sonriente" (Larrouy 1916:1). Por su parte, Nuestra Señora de Belén remite al dogma de la maternidad divina de María, proclamada en el Concilio de Nicea en el año 360. Esta advocación alude al lugar de nacimiento de Jesús, por lo que está vinculada al ciclo litúrgico de la Navidad en el calendario religioso. Al ser representada María con el niño Dios, al que sostiene en uno de sus brazos, desde la iconografía se encuadra dentro del grupo de las Vírgenes de Ternura, de origen gótico e influjo franciscano (Rodríguez G. de Ceballos 2001:31; Gómez Pérez 2016:283). En el Tucumán, la Inmaculada fue una de las advocaciones marianas con gran presencia devocional, a diferencia de la Virgen de Belén. La devoción de las feligresías hacia la Inmaculada se manifestó en la fundación de cofradías, en la celebración de su festividad en parroquias urbanas, en la presencia de imágenes de bulto en doctrinas rurales de pueblos de indios y en la denominación de lugares y propiedades (Larrouy 1915:65, 134; 1923:346, 376-377, 385; Quiroga 2001:170-171; Chaile 2011:39).

Consultamos correspondencia de agentes de la administración colonial y eclesiástica que contiene información acerca de las localidades del Valle y de Belén, referencias de los santuarios y descripciones de esos espacios. Estas fuentes están incluidas en recopilaciones documentales acerca de Tucumán y el culto a la Virgen del Valle (Larrouy 1915, 1923; Castro Olañeta 2017) o incorporadas en apéndices de otras publicaciones (Lafone Quevedo 1888; Serrano Redonnet 1992). Consideramos la dinámica de ocupación española en Belén y en Valle como asentamientos poblacionales con diferentes posibilidades de sostenimiento. Luego abordamos la conformación de cada santuario teniendo en cuenta el vínculo con la ocupación espacial, la consolidación como lugar de atracción de devotos y el equipamiento material a partir de las edificaciones.

\section{Catamarca en la frontera del Tucumán en el siglo XVII}

El paraje de Belén (Mapa 1) estaba comprendido en la jurisdicción de Londres, ciudad trasladada varias veces entre 1562 y 1633 por la resistencia de los indígenas del valle Calchaquí, además de conflictos entre pobladores y cuestiones vinculadas a la aridez y falta de agua (Lafone Quevedo 1888:29; Quiroga 2017:207). Durante las refundaciones tuvo nombres con advocaciones de santos: San Juan Bautista de la Rivera de Londres y San Juan Bautista de la Paz y una denominación que aludía la condición fronteriza con el valle Calchaquí: San Juan de la Frontera (Larrouy 1915:92-93; Larrouy 1923:52). A consecuencia del alzamiento general en el Calchaquí en 1632 se despobló para volver a ser ocupada después en Pomán (Lafone Quevedo1919:25; Olmos 1957:65). La actualización de la jurisdicción de Londres al fundarse San Juan Bautista de la Ribera (1607), cuya ubicación corresponde a la actual ciudad de Belén, tenía la intención de ejercer control en el área de la resistencia anticolonial (Hermitte y Klein 1972:5). A estas demarcaciones se sumaba la circunscripción eclesiástica del curato de Londres, establecido probablemente en 1607 por el obispo Trejo y Sanabria (Olmos 1957:58). Del 


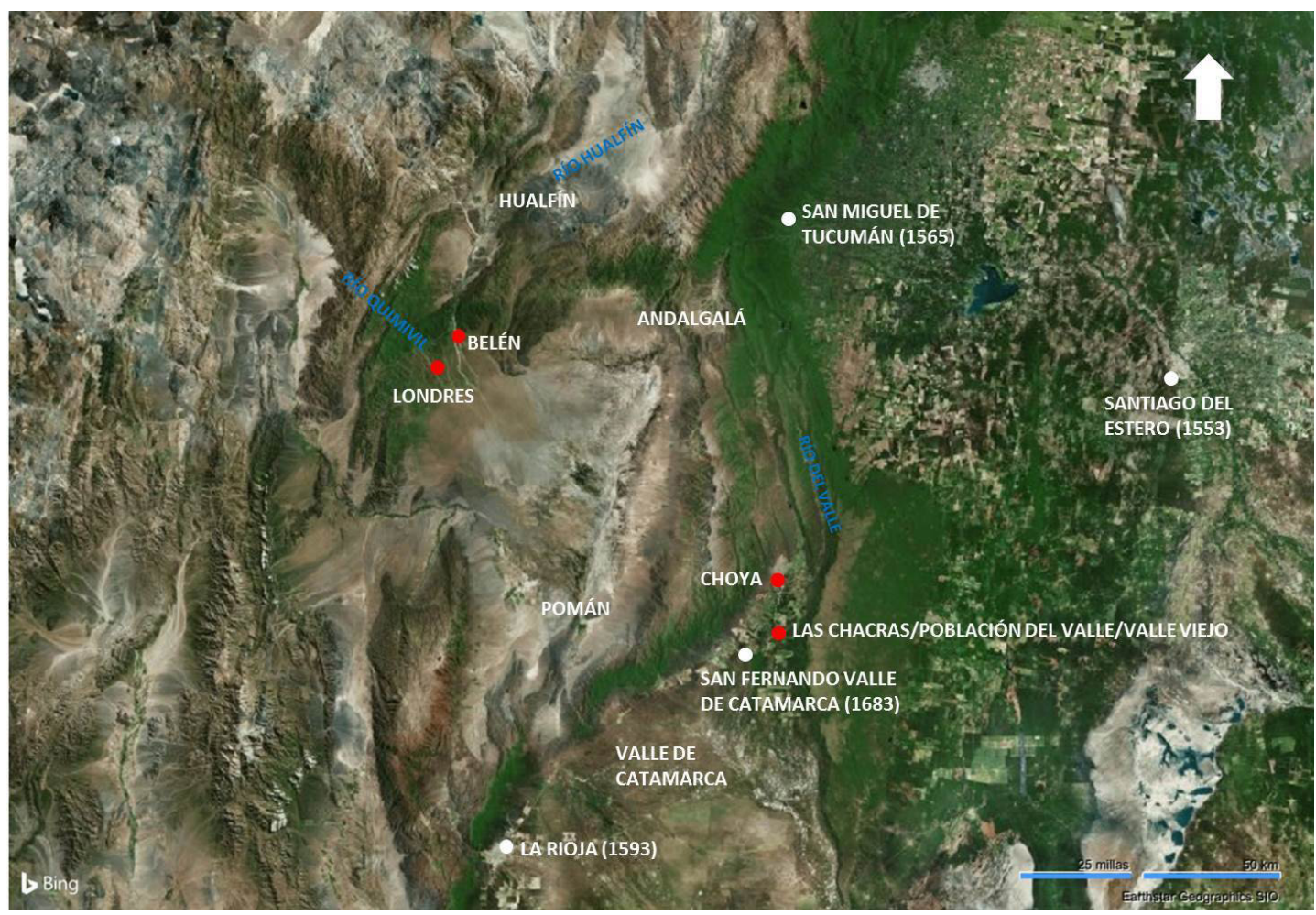

Mapa 1. Ocupación espacial en Catamarca en el siglo XVII. Elaboración: Cecilia Castellanos.

curato, describía el obispo Cortázar en 1621: "hay mucho número de indios, con sus distritos que es lo más penoso, y dificultoso del obispado" (Larrouy 1923:52). Después de sofocado el segundo alzamiento Calchaquí se produjo un intento de mudanza de Londres al Valle (Larrouy 1923: 171-172).

El Valle (Mapa 1) estuvo distribuido entre las jurisdicciones de Santiago, San Miguel y La Rioja (Brizuela y del Moral 2002:4). Vecinos de estas ciudades desarrollaban actividades ganaderas y agrícolas desde fines del siglo XVI (Assadourian 1982:200). Los agentes coloniales hicieron diversas demarcaciones territoriales en ese espacio. En la primera mitad del siglo XVII estaba incluido en partidos de territorialidad indígena (Castro Olañeta y Carmignani 2017:11-14, 18) y en el curato del Valle (Larrouy 1916:73).

El contexto postconquista Calchaquí implicó otorgamiento de encomiendas y tierras repartidas desde fines del decenio de 1660 entre quienes integraron las huestes, lo que derivó en la reconfiguración social, económica y étnica con el desarraigo y traslado de parcialidades indígenas por parte de sus encomenderos (Lorandi 1988; Rodríguez
2008). Las posibilidades de repoblamiento también involucraron las áreas del Valle y de Belén (Lorandi y Schaposchnik 1990:178-183; Vázquez 2009:7375). A inicios de la década de 1670 , el gobernador Peredo planteaba la conveniencia de mudar Londres al Valle, a solicitud de los habitantes de este último emplazamiento para "asumir categoría de ciudad y de cabeza de jurisdicción" (Serrano Redonnet 1992:98). En 1678, el gobernador Garro expresaba que en Londres no había pobladores españoles "en varias leguas" ni "en el sitio que llaman ciudad". En esta década los oficiales reales insistieron que en el Valle se verificaba mayor congregación y sustentaban el pedido de mudanza en las solicitudes de vecinos de Londres y del Valle y en el crecimiento "a número considerable de gente aquella población mediante un devoto santuario de la Inmaculada Concepción de Nuestra Señora" (Larrouy 1915:95). Unos años después, otra capilla a la que también algunos actores sociales reconocían la condición de santuario, comenzaba a adquirir importancia ligada a la ocupación espacial en uno de los parajes de Londres: Belén, esta vez por gestiones del sacerdote titular del curato. 


\section{El santuario de Nuestra Señora de la Purísima Concepción en el Valle}

La ocupación en el Valle dio lugar a la conformación del asentamiento más importante del espacio centro-oeste (Larrouy 1916:73; Brizuela del Moral y Acuña 2002:4). La zona donde estaba la iglesia que albergaba a la imagen mariana de la Purísima Concepción era conocida como Las Chacras, un enclave al noroeste. Desde 1668 pasó a ser Población del Valle por orden del gobernador; con calles, manzanas y solares, pero sin autoridades locales, por lo que los vecinos comenzaron a gestionar la fundación de una ciudad (Guzmán 2016: 34, 38). En comunicaciones de 1678, para justificar el pedido de mudanza de la ciudad de San Juan Bautista de la Rivera, el gobernador Garro decía que el Valle contaba con más recursos: tierra fértil, río, varias acequias, algarrobales, producción de trigo, maíz, frutas y la que se comercializaban con otros espacios -algodón con la región y pábilo enviado al Perú (Larrouy 1915:105-106)-. La Población del Valle tenía más habitantes españoles, vecinos y moradores, además de pueblos de indios y esclavos (Larrouy 1915:109); así como mejor ubicación para sostener un núcleo urbano, para ello resultaba central la devoción hacia la advocación mariana allí instalada (Larrouy 1915:93-95; Lorandi y Schaposchnik 1990:192-193). A principios de 1671, Peredo informaba:

hace poblado de poco tiempo a esta parte con número de más de ciento cincuenta vecinos, que llevados del cebo de su fertilidad y algodonales se han ido a vivir a él de diversas partes. Tiene una muy devota y milagrosa imagen de la Concepción Purísima que parece los ha traído a que la asistan en aquel paraje (Larrouy 1915:93).

Al triunfar la opción de mudanza, en 1679 el gobernador Mendoza Mate de Luna tenía que realizar el nuevo asentamiento y demarcar jurisdicción (Lafone Quevedo 1888:346-347; Olmos 1957:72). Este traslado en 1683 debía efectuarse a una legua de la Población del Valle, en la margen derecha del río, para garantizar un asentamiento urbano que gobernara la zona centro-oeste (Lafone Quevedo 1888:324-331). La instalación definitiva tardó hasta 1695 en consolidarse debido a la resistencia de los habitantes de Población del Valle -denominado
Valle Viejo desde la fundación de San Fernandoy a presentaciones del cabildo de La Rioja por pérdida de jurisdicción (Lorandi y Schaposchnik 1990:178-183). Vecinos y moradores permanecieron en este sitio hasta la intimación del lugarteniente de gobernador Bartolomé de Castro, comisionado por el gobernador Jáuregui para dar cumplimiento a la mudanza (Serrano Redonnet 1992:114-118). Una vez construida la nueva capilla, se trasladó la imagen de la Concepción y con ello se culminó la fundación de la ciudad de Catamarca (Guzmán 2016:39).

Con la devoción mariana, que luego se conocería con el título de Virgen del Valle, se logró consolidar la ocupación de la zona centro oeste en los núcleos donde estuba su templo. Decía Peredo que "la milagrosa imagen que tienen de la Purísima Concepción de Nuestra Señora en cuyo culto e iglesia acuden con mucha devoción" consiguió congregar a vecinos y moradores del Valle (Larrouy 1915:95). Información acerca de la presencia y actividades de la iglesia de la Concepción fue incorporada a la correspondencia en la que los gobernadores Peredo y Garro referían a la necesidad de mudanza, sumando argumentos para justificarla (Larrouy 1915:93,95, 106).

La iglesia de la Concepción en Las Chacras, que existía a inicios de la década de 1640 (Olmos 1957:58), fue fabricada con aportes del gobernador Mercado y Villacorta, según informaba Peredo (Larrouy 1915:95). En este templo, en 1648 el obispo Maldonado instituyó cofradía, y al finalizar las guerras Calchaquíes los vecinos nombraron patrona del Valle a la imagen de la Inmaculada por la protección ejercida a este espacio (Larrouy 1915:134; Capurro 2017:24-25). La vinculación entre la advocación y la guerra con los indígenas es uno de los elementos reiteradamente recuperados en relatos de la Información Jurídica respecto de la Historia de Nuestra Señora del Valle de $1764^{5}$ que refieren a la protección de españoles y del poblado. Capurro plantea que los relatos de algunos de los testigos remitirían a las últimas campañas contra los indígenas entre 1657 y 1659. A partir del análisis del documento, esta autora examina las formas de intervención de la Virgen, consistentes en desapariciones de la imagen desde la capilla hacia lo que los devotos identificaron con el valle Calchaquí, apariciones durante enfrentamientos entre españoles e indios, protección de un indio mensajero aliado a los españoles y aparición ante indígenas que trataban de atacar el poblado (2017:50-60). 
Fue durante ese contexto bélico regional, en el que las milicias de la gobernación estaban abocadas a la campaña militar (Larrouy 1916:88) y concentradas en Salta, cuando se concretó en 1658 una ceremonia de reconocimiento y promoción del culto mariano en la advocación de la Concepción en esta ciudad. Los cabildantes salteños, a propuesta del gobernador Mercado y Villacorta, realizaron en el templo de los franciscanos y ante el vicario foráneo Carrizo de Hores, el juramento de defender los principios inmaculistas ${ }^{6}$. En el acta de juramento los regidores dejaban expresado que el gobernador

propuso, y votó en la ciudad de Cordova $\mathrm{y}$ otras partes, a que todos en un cuerpo votemos y juremos sentir y defender aver la dicha Santissima Reyna de los Angeles y nuestra, concebida desde el primer instante de su Concepcion sin pecado original, y sobre ello si fuere necessario dar las vidas y derramar la sangre ${ }^{7}$.

Del curato denominado Nuestra Señora de la Concepción del Valle de Catamarca, el obispo Maldonado expresaba que es

uno de los primeros beneficios de la provincia por el Santuario de ella, donde por los muchos milagros de esta Santa Imagen el mayor numero de sus habitadores es toda gente española, vecinos de la ciudad de La Rioja y Londres, y muchos de ellos naturales del dicho Valle de Catamarca (Larrouy 1915:64).

La condición de santuario aparece mencionada desde antes de la década de 1670 por habitantes del Valle y autoridades políticas y religiosas. La documentación registra menciones para 1648 y 1653 (Larrouy 1915:64,69). En 1673 Peredo destacó que la "milagrosa imagen" de la Concepción atraía moradores "en cuyo culto e Iglesia acuden con mucha devoción" (Larrouy 1915:95, 109). A la iglesia, el gobernador Garro la reconocía como santuario en 1678 por "la gran devoción que toda la provincia tiene a la Inmaculada Imagen de Nuestra Señora de la Concepción" hacia donde llegaban "de varias partes y por dilatados caminos en romería innumerables gentes" (Larrouy 1915:111). Córdoba y Santiago del Estero eran espacios desde donde arribaban peregrinos a solicitar gracias y a cumplir promesas, cuyos primeros registros datan de 1653 (Larrouy 1915:69,83). Una declaración del sargento mayor Pedro Arias, en 1700, recuperaba el caso de un peregrino:

un fulano Ardiles que asistía en la ciudad de Córdoba, porque estando sin vista, y habiendo venido a este Valle al recurso de esta Santa Imagen milagrosa, y haciendo su novenario, le volvió la vista que tenía perdida (Larrouy 1915:81-82).

A pesar de su importancia cultual, no siempre el edificio estuvo en condiciones adecuadas. Al iniciar la década de 1670, el techo fue cubierto de tejas por indígenas del Chaco, a cuyo trabajo "se le aplicó la composición de tres familias de limosna" (Larrouy 1915:95). Para 1690 el cabildo y autoridades religiosas acordaron la reparación de la iglesia (Larrouy 1915:136). El traslado definitivo de Valle Viejo también implicaba la construcción de una nueva capilla, cuya construcción fue solventada por Bartolomé de Castro (Serrano Redonnet 1992:104-109). La edificación era una

capilla decente de hermosas tapias, tijera corrida, ventanas y puertas con llave, adonde se colocó el Santísimo Sacramento y la Purísima Concepción de la Virgen María, abogada de esta ciudad, con toda grandeza, y el dicho día poner mesa franca para todos los que vinieron en procesión acompañando a sus Divinas Majestades (Serrano Redonnet 1992:118).

Castro también se ocupó de que se abriera "camino de más de una legua de montaña para que viniese la procesión desde el Pueblo Viejo a esta ciudad con toda decencia, y en medio del camino está un río grande, e hizo un puente para que pasase el pueblo a pie enjuto" (Serrano Redonnet 1992:119). Hasta la primera mitad del siglo XVIII esta capilla pequeña reemplazaba a la iglesia matriz, ya que la parroquia se encontraba "a los principios su fábrica”, funcionando como el espacio cultual para la celebración "de la misa y demás ministerios y festividades, con tanta incomodidad que toda la mayor parte del pueblo se quedan sin consuelo de poder asistir por la gran estrechez y cortedad" (Larrouy 1915:165, 170). 
Es posible observar un proceso de transferencia y suplantación de nominaciones entre el espacio y la advocación mariana. Denominaciones indicativas de devoción hacia la Inmaculada se hallan en el pedido de 1623 para medición y amojonamiento de una merced de tierra solicitada por Manuel de Salazar (Larrouy 1915:20), quien fue su primer sacristán (Lorandi y Schaposchnik 1990:187). El topónimo también aparece utilizado en 1648 para designar al curato (Larrouy 1915:64) y en el acta de demarcación territorial de 1684 de la ciudad de San Fernando (Lafone Quevedo 1888:349). Como título de la advocación mariana persistió hasta finales de la primera parte del siglo XVIII, frente al uso más restringido, entre la feligresía, de la nominación "del Valle" durante la segunda mitad del siglo XVII (Larrouy 1915:78). La denominación se impuso desde 1761 a partir del pedido del procurador para levantar la Información Jurídica.

\section{El santuario de Nuestra Señora de Belén en el paraje homónimo}

Belén tenía una posición estratégica que le permitió conformarse en un "importante nudo comercial" en el oeste (Hermitte y Klein 1972:4-5) dentro de la jurisdicción de Londres, a principios del siglo XVII (Quiroga 2015:9-10). De la "puna de Londres" decía el gobernador Ribera que era "refugio de indios rebeldes" y "área de trajines" que vinculaba Atacama, Salta, Jujuy y Alto Perú (citado en: Quiroga 2015:9). Belén formaba parte de un espacio mayor eminentemente indígena en el que, hacia la década de 1640, circulaban o permanecían unos pocos agentes coloniales. Se encontraban feudatarios, pobleros y sus familias, soldados, algunas autoridades, el sacerdote beneficiario del curato, misioneros jesuitas y mercedarios que colaboraban en "doctrinar y predicar a los naturales" que se hallaban encomendados y quienes mantenían contacto con indios del Calchaquí, como ocurría en el fuerte de Pantano donde había parcialidades Andalgalas (Larrouy 1923:168-172). En el contexto de los pedidos de mudanza en el decenio de 1670, el topónimo empleado era el de San Juan Bautista de la Rivera de Londres.

En la segunda mitad del siglo XVII, los territorios que estuvieron involucrados en la resistencia Calchaquí, por su condición de rebeldía o por su proximidad, asistían a una reorganización con la entrega de encomiendas, la desnaturalización de algunos grupos indígenas y la reubicación de otros.
Belén fue uno de los focos rebeldes en el ataque a San Juan Bautista de la Rivera por grupos indígenas Malfines y Abaucanes durante el alzamiento general en el decenio de 1630 que puso en peligro la colonización de ciudades vecinas (Schasposnick 1996:387-391), así como de escaramuzas recurrentes en la primera parte de la década siguiente (Quiroga 2017:209-210). Hacia fines del siglo XVII, esta memoria acerca de la resistencia calchaquí permanecía fresca entre españoles y era expresada con temor y desconfianza hacia una rebeldía latente de los calchaquíes (Larrouy 1923:409).

Belén contaba con poblados agregados indígenas ${ }^{8}$ que se mantuvieron ocupados hasta mediados del siglo XVII (Quiroga, 2011) y con grupos de encomendados sometidos a una explotación desmedida y maltratos (Schasposnick 1996: 386-387; Quiroga 2012). Es preciso tener en cuenta el proceso de entrega de mercedes de tierras luego de culminada la guerra en 1665. A diferencia de lo que ocurrió en Punta de Balasto, sector sur del valle de Yocavil, al este de Belén, algunos españoles que recibieron mercedes de tierras y no las ocuparon (Rodríguez 2008:69, 74); en el norte de Belén se produjo una apropiación del espacio mediante la ampliación de propiedades de encomenderos (Quiroga 2001:165). Fue en ese momento de reorganización cuando se institucionalizó la devoción de Belén, unos pocos años después del poblamiento del paraje a partir de una merced de tierras y que corresponde al período en el que los españoles bregaban por consolidar el dominio del espacio, de manera desigual según las zonas aptas para determinadas producciones y por la mano de obra con más ahínco en los valles de Catamarca. Estos procesos fueron paralelos a los pedidos de traslado de Londres al Valle en la década de 1670 y a las descripciones poco alentadoras acerca de este núcleo y sus jurisdicciones: "áspero y estéril de los caminos", "que la fragosidad y esterilidad de la tierra ha ahuyentado sus habitadores", con "todas las encomiendas muy disipadas, de las cuales por lo extraviado de sus habitaciones y ser el mismo camino retirado del tráfico no tienen aprovechamiento". De "los indios de aquellos parages", Garro indicaba "la falta de educación cristiana que tienen [...] porque aunque quiera su doctrinante administrársela, están en tan divididas distancias que se hace dificultoso" (Larrouy 1915:105). Con "pueblos" separados por grandes extensiones y "un solo cura que hay de Españoles e Indios" se dificultaba la atención religiosa y tampoco alcanzaba con la colaboración de misioneros jesuitas (Larrouy 1915:110-111). 
Para 1692, Bartolomé Reyes, quien fue cura de Londres durante diez meses, decía que dicho beneficio "tiene contorno de ciento y cincuenta leguas", ocho pueblos de indios y que como estipendios solo percibió "calzón y ongarina de pañete por la limosna de unas misas, con más de ocho pesos que el día de Rusurreción le dieron algunos españoles e indios de limosna" (Larrouy 1923:374-375). En este contexto de un espacio que, como cura atendía y conocía, Bartolomé Olmos y Aguilera ${ }^{9}$ estaba interesado en consolidar la ocupación del paraje de Belén antes de la fundación de San Fernando, para ello, la cuestión de las tierras y la devoción a la Virgen resultaron primordiales. La donación de tierras realizada por este sacerdote dio origen al poblado de Belén vinculado a un santuario de la Virgen María en esta advocación (Larrouy 1915:115; Olmos 1957:82). Olmos era cura y vicario eclesiástico de la ciudad de San Juan de la Rivera de Londres y, según informaba el teniente de gobernador de La Rioja, hacia 1681 tenía "como a tiempo de siete años" de cura de indios y de españoles en esa jurisdicción (citado en Montes 1958:23). En el paraje de Andalgalá actuaba como "cura doctrinante" de tres pueblos de indios (Montes 1958:23). En 1678 peticionó una merced de tierras y de agua en un sector de Londres "para estar en el conmedio", es decir, en el corazón de ese espacio ${ }^{10}$. Sostenía el pedido en la necesidad de tierras para mantenerse, tener morada, sementeras y cabalgaduras que le permitieran "correr la jurisdicción de Londres para la administración de los sacramentos". Solicitó merced "en forma de un sitio que cae a la salida de el Río de Malfín a la parte de una población y estancia vieja de los que fueron moradores de Londres, al lado que cae la ciudad vieja, que de ellas al dicho sitio hay cuatro leguas" (Larrouy 1915:112-121) y que correspondía a tierras en el valle de Famayfil (Vázquez 2007:10), como también se denominaba al valle de Belén (Lafone Quevedo 1919:11). Esta referencia de "ciudad vieja" remitía a San Juan de la Rivera de Londres (Serrano Redonnet 1992:96).

En el documento de donación el sacerdote detallaba las actividades que desarrolló en Belén: poblamiento, construcción de iglesia y casas, y mejoras (puesta de acequias, árboles y ganado), en un sitio que "ha más de 30 años" que estaba "desierto y despoblado y sin dueño" (Larrouy 1915:112-121). Para ese momento, el territorio surcado por el río y ubicado en el camino hacia Andalgalá era zona de "chacras" (Larrouy 1915:115), también fueron instándose estancias (Castro Olañeta 2017:235). A inicios del decenio de 1680, el paraje donde estaban ubicadas estas tierras se denominaba Nuestra Señora de Belén. En diciembre de 1681, Olmos otorgó la posesión a la Virgen de Belén y procedió a repartir "entre pobres las dichas tierras o cuadras" y las que quedaban sin asignar les correspondería a curas y al obispo hacer la distribución (Larrouy 1915:115-116). La relación entre tierras y advocaciones marianas se verificó también en otras áreas de Catamarca. Fueron casos de donación, en San Fernando, a la Virgen del Valle por parte de mujeres viudas en el siglo XVIII: una chacra por doña Antonia Herrera y Ahumada y una suerte de tierras en el paraje Yerba Buena, curato de Ancasti, por doña María de Toledo (Larrouy 1915:139). En el valle de Santa María, el maestro de campo Fernando Lisperguer y Aguirre, vecino feudatario de Salta, vendió en 1714 una "suerte de tierra con agua nombrada Santa María", la escritura de compraventa establecía "mejoras" para que la "devoción" de Lisperguer y la de su esposa "se consuman en culto y reverencia de la Virgen Santísima" de la Candelaria "en la iglesia de este sitio" (citado en Rodríguez 2008:73).

Una de las formas de incentivar la permanencia de la población establecida en Belén fue mediante el parcelamiento de la tierra, cuyos pagos por usufructo ("dar cada año dos pesos para la Virgen Santísima de Belén, en señal de tributo") serían destinados a la compra de ornamentos y adornos de la iglesia, solventar la celebración de las fiestas de Pascuas de Navidad y pago al sacerdote que oficiara las misas del novenario. Estas misas también se pagaban con "las limosnas que juntase el Mayordomo de la Virgen". Así lo establecía el sacerdote en el documento de donación en 1681, en el que también fundó la cofradía de Nuestra Señora de Belén (Larrouy 1915:115-116). Se trataba de una práctica común de las cofradías solventar festividades con financiamientos provistos por las fábricas y las limosnas de los devotos (Capurro 2017:65-69). En el caso de la advocación de la Concepción también tuvieron importancia significativa las limosnas y las donaciones a la cofradía (Larrouy 1915). El cura además estipulaba detalles para el reparto del agua y el cuidado de acequias, aspecto vital en un espacio donde el acceso a este recurso disputado demandaba esfuerzos (Quiroga 2001:182). Solo algunos dueños de cuadras recibieron un reparto de agua, se trataba de españoles y la Virgen de Belén, y dos para los sacerdotes. Entre las receptoras estaba "una hija de 
Julián de Herrera", quien la obtuvo para "remedio" (Larrouy 1915:119). Este uso terapéutico del agua que se proveía fue posiblemente común entre los devotos. Olmos indicaba que "en tan breve han visto tan grandes milagros que ha sanado enfermos, dado el habla a una pública muda" (Larrouy 1915:117).

Olmos esperaba que el gobernador del Tucumán "ha de sanctar [sic] este nuevo santuario como lo han hecho sus antecesores" al poner nombre a la iglesia de Sumampa -jurisdicción de Santiago del Estero- y a la iglesia de la Población del Valle, por lo que le solicitaba "admita el patronazgo" de la iglesia de Belén: "no ha de ser menos Su $\mathrm{S}^{\text {ria }}$ que sus antepasados, del alivio y consolación de los pobres que aquí se han juntado, pende inmediatamente de su patrocinio y amparo" (Larrouy 1915:118). También disponía que ningún ornamento ni imágenes fueran llevados a doctrinas ni "a ningún paraje por acomodado que sea" (Larrouy 1915:120). Probablemente estas disposiciones eran por los pedidos de traslado de Londres.

Aunque en la zona se ubicaban asentamientos que estaban dispersos, es probable que la iglesia que albergaba la imagen de Belén en el oeste catamarqueño fuera una de las aglomeraciones que garantizara la afluencia de gente. El sacerdote era explícito al señalar que las cofradías posibilitaban "la congregación de gente devota", acción que:

se ha intentado porque en tierras tan dilatadas como estas hay por esos despoblados muchos pobres retirados, que, por no haber tenido este pensamiento, no oyen misa ni conocen a Dios Nuestro Señor, ni están en la perfección cristiana, sus hijos sin doctrina, sus almas sin remedio, sus personas que pueden servir al Rey nuestro señor para sus guerras y diligencias, estarán en un cuerpo para acudir a la voz de Su Magestad, trabajarán y aumentarán diezmos, vivirán y cumplirán como cristianos (Larrouy 1915:119-120).

A fines del siglo XVII, en el conjunto de testimonios de los curatos de indios del Tucumán, Bartolomé Reyes, ante el provisor y vicario general del obispado, describía a la iglesia de Belén como

una iglesia vieja de paredes pequeñas, con techo terrado, y en el altar mayor ornato de frontal razonable, con su cielo y dosel, que no se acuerda de que es, y una imagen de Nuestra Señora en su cajón por dentro, y todo el ornato necesario para celebrar el santo sacrificio de la misa; no es pueblo de indios, sino un lugar dedicado para dicha imagen (Larrouy 1923:375).

Era la iglesia mejor provista en el espacio del curato, donde predominaba el estado deplorable de las capillas de los pueblos de indios, en los casos en los que contaban con ellas (Larrouy 1923:374-375).

La advocación de Belén nominaba al sitio donde se estaba consolidando una ocupación española y mestiza a partir de la distribución de cuadras realizada por el sacerdote entre "muchos pobres que han servido a Su Magestad en la conquista del Calchaquî" y quienes "por no saber leer ni escribir no salen a los poblados a pedir a un Gobernador donde vivir, ni tienen morada cierta" (Larrouy 1915:120). En el mismo año, el sitio era también recomendado por el cabildo de San Fernando de Catamarca en 1692 como lugar apropiado para adelantar la plaza de cobro de la aduana por tener "mejor disposición" que los de Córdoba al "ser el único y preciso paso" del camino "que pasa por el valle Calchaquín" (Larrouy 1923:420). En las últimas décadas del siglo XVII, en un curato que tenía también pueblos de indios, el paraje tomó el nombre de una advocación mariana que respondía a una devoción particular, iniciando un proceso de afianzamiento de la ocupación que terminó de afianzarse en el siglo XVIII (Hermitte y Klein 1972:8-11).

\section{Conclusiones}

Los santuarios de la Concepción/del Valle y de Belén tuvieron un rol significativo en la consolidación del dominio colonial en Catamarca, problemática que se inserta en los planteos en torno a la conformación del culto mariano en Hispanoamérica, abordada por diversa/os autora/es. En este proceso complejo que comprende varios aspectos consideramos la relación entre devoción/espacio religioso y ocupación territorial. Belting plantea que las advocaciones religiosas que generan devoción suelen cumplir "una función relacionada con el lugar" en el que se desarrollan. La singularidad de los títulos permite diferenciarlas de un conjunto de imágenes de la misma advocación que podían encontrarse en otros espacios, lo que se evidenció en especial en el caso de la Concepción/del Valle. Además, el prestigio 
que adquirían ciertas advocaciones consideradas milagrosas redundaba en que sus lugares de culto se conformaran en centros de atracción (Belting 2009:56-57), de allí su reconocimiento como santuarios por los actores sociales.

La instalación del santuario de la Concepción/ del Valle remite a la guerra contra los indígenas Calchaquíes y a la disputa por el espacio. Si bien el territorio que se configuró como Catamarca tiene varios espacios con la condición geográfica de valle, fue la Población del Valle/Valle Viejo la que conservó esa denominación para un asentamiento y la que traspasó a la advocación mariana en un proceso de retroalimentación entre culto y consolidación de la ocupación espacial en la que intervinieron varios agentes sociales que eran pobladores feligreses, peregrinos y agentes de las administraciones real y eclesiástica.

Mientras que el santuario de Belén se conformó después de la derrota definitiva de las poblaciones, en contexto de traslados de grupos indígenas. Belén fue un espacio asociado a la resistencia Calchaquí y con población indígena y mestiza dispersa, a diferencia del Valle donde existieron núcleos de ocupación española desde mucho antes. Quizás ello también haya incidido en la promoción de la devoción del Valle por parte de autoridades reales, debido a la necesidad de consolidar un núcleo poblacional español externo a los espacios que fueron foco de resistencia, donde los indígenas sostuvieron su autonomía hasta antes de la desnaturalización definitiva (Quiroga 2011:303). Es probable que lo tardío de un asentamiento poblacional en Belén se relacionara con precauciones respecto de no dar lugar a posibles rebeliones de indios encomendados en ese espacio. No resulta casual que después de la derrota Calchaquí la ocupación de la zona oeste pudiera organizarse con la formación de pueblos (Guzmán 2016:31,35) y la apropiación del territorio mediante propiedades rurales (Quiroga 2001:171-75). La instalación del santuario tuvo lugar en un núcleo donde principalmente se concentraron españoles y al que también asistían indígenas.

Hubo un proceso de más larga duración durante el siglo XVII en la institucionalización de la advocación de la Concepción/del Valle, inscripto en una difusión regional del culto inmaculista y luego del Valle con las peregrinaciones. Por su parte, el caso de Belén, de instalación reciente al iniciar el decenio de 1680, surgió a partir de un proceso de apropiación del espacio mediante una merced de tierra y de la gestión eclesial y fervor devocional de un actor que conocía la jurisdicción y disponía de los medios y las vinculaciones necesarias para concretar una rápida institucionalización. En este crecimiento del espacio religioso, los pobladores feligreses también tuvieron participación al contribuir en el sostenimiento material del culto y al prestigio de la advocación como milagrosa.

\section{Agradecimientos}

Agradecemos los comentarios de Silvia Palomeque, Laura Quiroga y Cecilia Castellanos. Así también las valiosas sugerencias de las/os evaluadoras/res.

\section{Referencias Citadas}

Anrup, R.

1998 "La Virgen María en la imaginería iberoamericana". En América Latina: ¿y Las Mujeres Qué? (Workshop-Seminario Investigaciones Nórdicas Sobre la Mujer en América Latina), editado por María Gabriela Medina, Instituto Iberoamericano, Universidad de Gotemburgo, Suecia.

Assadourian, C. S.

1982 El Sistema de la Economía Colonial. Mercado Interno, Regiones y Espacio Económico. IEP. Lima.

Belting, $\mathrm{H}$.

2009 Imagen y culto: una Historia de la Imagen Anterior a la era del arte. Akal, Madrid.

Brizuela del Moral, F. y Acuña, M. I.

2002 La jurisdicción territorial de Catamarca. Ponencia presentada en el Congreso Regional de Ciencia y Tecnología NOA, Catamarca.
Capurro, N.

2017 El culto a la Virgen del Valle de Catamarca: Actores, usos y Apropiaciones de un culto Mariano Colonial. Tesis de Licenciatura en Ciencias Antropológicas, Universidad de Buenos Aires, CABA, Argentina.

Chaile, $\mathrm{T}$.

2011 Devociones Religiosas Procesos de Identidad y Relaciones de poder en Salta. Desde la Colonia hasta Principios del siglo XX. Fondo Editorial Fundación CAPACIT-AR del NOA. Salta.

Christian, W. 1991 Religiosidad local en la España de Felipe II. Nerea, Madrid.

Castro Olañeta, I.

2017 La Visita Del Oidor Antonio Martínez Luján del Vargas a Las Encomiendas de Catamarca, Santiago Del Estero y 
Salta. Gobernación Del Tucumán, 1693-1694. Ferreyra Editor, Córdoba.

Castro Olañeta, I. y Carmignani, L.

2017 "La Sierra de Santiago y el Valle de Catamarca (Gobernación del Tucumán) a Principios del siglo XVII: Refexionando sobre una nueva Regionalización". Prohistoria 27.

Fogelman, P.

2002 "Reconsideraciones sobre los Orígenes del culto a la Virgen de Luján". Entrepasados 23:123-148.

Freedberg, D.

2009 El poder de las Imágenes, Estudios sobre la Historia y la teoría de la Respuesta. Cátedra, Madrid.

Gómez Pérez, E.

2016 "La Virgen de Belén y su devoción en el camino de Santiago. Su patronazgo en Carrión de los Condes (Palencia)". En Regina Mater Misericordiae. Estudios Históricos, Artísticos y Antropológicos de Advocaciones Marianas, coordinado por Juan Aranda Doncel y Ramón de la Campa Carmona, pp. 283-299, Litopress, Córdoba, España.

Guzmán, F.

2016 Los Claroscuros Del Mestizaje: Negros, Indios y Castas en la Catamarca Colonial. Encuentro Grupo Editor. Córdoba.

Hermitte, E. y Klein, H.

1972 "Crecimiento y estructura de una comunidad provinciana de tejedores de ponchos: Belén 1678-1869". Documento de Trabajo 78.

Lafone Quevedo, S.

1888 Londres y Catamarca, Cartas A La Nación 1883/85. Imprenta y Librería de Mayo, Buenos Aires.

Larrouy, A.

1915 Documentos Relativos a Nuestra Señora Del Valle de Catamarca, Tomo Primero (1591-1764). Compañía Sudamericana de Billetes de Banco, Buenos Aires.

Larrouy, A.

1923 Documentos Del Archivo de Indias Para la Historia Del Tucumán, T. $1^{\circ}$ (1591-1700), L. J. Rosso y Compañía Impresores, Buenos Aires.

Larrouy, A.

1916 Historia de Nuestra Señora del Valle. Compañía Sudamericana de Billetes de Banco, Buenos Aires.

Lorandi, A. M. y Schaposchnik, A.

1990 "Los Milagros de la Virgen del Valle y la Colonización de la Ciudad de Catamarca". Journal de la Societé des Americanistes 76:177-198.

Montes, A.

1958 "Encomiendas de indios Diaguitas Documentadas en el Archivo Histórico de Córdoba". Revista Instituto de Antropología II-III:1- 28.

Prat i Carós, J.

1989 "Los santuarios marianos en Cataluña: una aproximación desde la etnografía". En La religiosidad popular, Tomo III, coordinado por Álvarez Santaló, Carlos et al., pp. 211-252, Anthropos, Barcelona, España.

Quiroga, L.

2001 Paisaje y Relaciones Sociales en el Valle de Cotagua. Del Tardío Prehispánico a la Ocupación Colonial. Tesis Doctoral en Antropología, Universidad de Sevilla, España. Quiroga, L.

2011 "Al abrigo de sus huaycos: narrar la Geografía, Habitar los Espacios, Interpretar las Prácticas”. En Las Tierras Altas del Área Centro Sur Andina, entre el 1000 y el 1600 d.C., editado por María E. Albeck, Beatriz Cremonte y Marta Ruiz, pp. 285-310. Universidad de Jujuy, Jujuy, Argentina. Quiroga, L.

2012 Las Granjerías de la tierra: Actores y Escenarios del Conflicto Colonial en el valle de Londres (Gobernación del Tucumán, 1607-1611). Surandino Monográfico, segunda sección del Prohal Monográfico 2.

Quiroga, L.

2015 Del Páramo a la puna. Textos y Contextos Arqueológicos para una Descripción del Paisaje Altoandino en la Gobernación del Tucumán. Corpus 5, 2.

Quiroga, L.

2017 "Entramados Rebeldes de puna y valles en el Tucumán (siglo XVII). Valle de Londres, Provincia de los Diaguitas. Una Perspectiva Cartográfica”. Estudios Atacameños 75:203-218.

Rodríguez G. de Ceballos, A.

2001 "Trampantojos a lo divino: íconos pintados de Cristo y de la Virgen a partir de imágenes del culto en América meridional". Actas III Congreso Internacional del Barroco Americano: Territorio, Arte, Espacio y Sociedad, Universidad Pablo de Olavide, Sevilla, España.

Rodríguez, L.

2008 Después de las Desnaturalizaciones: Transformaciones Socio-económicas y Étnicas al sur del Valle Calchaquí Santa María, fines del siglo XVII-fines del siglo XVIII. Antropofagia, Buenos Aires.

Saignes, T.

1992 "De los Ayllus a las Parroquias de Indice: Chuquiago y la Paz". En Ciudades de los Andes. Visión histórica y contemporánea, dirigido por Eduardo Kingman Garcés. IFEA. https://books.openedition.org/ifea/2244 (17 febrero 2021).

Schaposchnik, A.

1994 "Aliados y Parientes. Los Diaguitas Rebeldes de Catamarca Durante el gran Alzamiento". Histórica 2:383-416.

Serrano Redonnet, J.

1992 "Documentación Referente a la Fundación Efectiva de Catamarca. Genealogía". Revista del Instituto de Ciencias Genealógicas 25: 95-125.

Soprano, P.

1889 La Virgen Del Valle y la Conquista Del Antiguo Tucumán, Imprenta del Courrier de La Plata, Buenos Aires.

Tell, S.

2017 "Los autos de ejecución de las sentencias del visitador Luján de Vargas a los encomenderos de Córdoba (16931694)". Corpus 7, 2.

Vázquez, $\mathrm{F}$.

2007 La Resignificación de la Identidad como Estrategia de Resistencia frente al Dominio Colonial. Belén. Ponencia presentada en las IV Jornadas de Jóvenes Investigadores, Buenos Aires, Argentina.

Vázquez, $\mathrm{F}$.

2009 Lugar de origen, lugar de Residencia. Territorialidad y Resignificación de Identidades. El caso de los Tinogasta en Belén, Catamarca, siglos XVIII y XVIII. Tesis para optar por el grado de Licenciatura en Historia, Universidad de Buenos Aires, Buenos Aires, Argentina. 


\section{Notas}

1 William Christian define a los santuarios como lugares "que atraían devotos de más de una población, que eran metas de enfermos o que tenían una especial consideración en la devoción de las gentes" (1991:97). Las zonas donde suelen haber santuarios presentan condiciones propicias para el asentamiento de población y son cercanos a caminos (Prat i Carós 1989: 229).

2 Durante la guerra Calchaquí, en los siglos XVI y hasta mediados del XVII, los fuertes que se fundaron dependientes de las jurisdicciones de las ciudades involucradas en las campañas, también fueron nombrados en su mayoría con advocaciones de santos (Larrouy 1923).

3 Varios de los títulos marianos que adquirieron notoriedad durante el periodo colonial en espacios locales de América Hispana correspondan a la advocación de la Inmaculada. Además del caso de la Virgen del Valle en Catamarca, también se configuraron otros cultos en territorios que en la actualidad son parte de Argentina: Virgen de Luján en el Río de la Plata, de Itatí en Corrientes, y del Milagro y las Lágrimas en Salta (Chaile 2011:39-40).

$4 \quad$ Franciscanos y jesuitas fueron defensores de este principio ante quienes sostenían lo contrario, tuvo también el apoyo de algunos pontífices de Roma y el respaldo de la Corona española (Anrup 1998).

5 La Información se levantó a partir de los pedidos del procurador de la ciudad de Catamarca con la finalidad de informar acerca de los prodigios de la Virgen del Valle, su origen y la condición de mediadora y patrona de españoles (Larrouy 1915:192).

$6 \quad$ El acto se insertaba además en las disputas europeas acerca de la adhesión a la idea de la concepción inmaculada de María. En la primera mitad del siglo XVII, el rey y las cortes habían efectuado el mismo juramento que luego se realizó en varias ciudades de América (Chaile 2011:38-39)

7 Archivo General de la Nación, VII, 653.

8 Estaban enclavados en cerros y quebradas, donde los grupos indígenas practicaban una agricultura de riego. Tenían una arquitectura integrada al relieve serrano que permitía combinar una estrategia defensiva eficaz. Fueron espacios de sociabilidad y reproducción social que durante la resistencia calchaquí conformaron escenarios de guerra y por ello atacados por españoles (Quiroga, 2011). Esta forma de habitar ha sido registrada por la arqueología para poblaciones de los valles durante el periodo de desarrollos regionales o tardío.

$9 \quad$ Hijo del maestre de campo don Bartolomé de Olmos y Aguilera (Comisario Real de la Caballería y encomendero de Montos y Nonsacate, jurisdicción de Córdoba) (Larrouy 1915:113; Tell 2017:15.

10 Tomamos la referencia de Saignes (1992). 